\title{
JURISDIÇÃO AMBIENTAL APÓS BRUMADINHO: CAMINHOS PARA EFICIENTE GOVERNANÇA DOS DESASTRES A PARTIR DO DIREITO COMPARADO
}

\author{
Pedro Henrique Moreira da Silva ${ }^{1}$ \\ Pedro Henrique Cordeiro Gonçalves ${ }^{2}$
}

\section{RESUMO}

O estudo suscita o direito dos desastres a partir das discussões iniciais sobre a sociedade de risco. Dessa forma, reconhecendo o contexto do risco, a partir das perspectivas de Ulrich Beck, são pontuadas as questões das barragens de rejeito de mineração, o potencial de desastres que acompanha estes empreendimentos, e a relação desses riscos com a tragédia em Brumadinho/MG. A partir desse ponto, o artigo objetiva discutir, de forma crítica, a gestão executiva e jurídica do referido desastre, com 0 questionamento acerca da eficiência do direito dos desastres brasileiro na prevenção e gestão de emergências. Para responder à questão, recorreu-se ao direito comparado, ao método hipotético-dedutivo e dialético, com pontuações qualitativas, para apresentar o direito dos desastres estadunidense e europeu como modelo para uma nova jurisdição ambiental no Brasil. Assim, o que se concluiu foi a necessidade de manter a operacionalidade e permanência do Direito, traçar estratégias de estabilização e identificação de vítimas, reduzir vulnerabilidades futuras, integrar órgãos do Estado e estruturar um planejamento preventivo eficaz - a partir de uma jurisdição sólida. Dessa forma, foi apontada a necessidade de um direito dos desastres baseado na prevenção de emergências, o que justifica o trabalho.

Palavras-chave: Direito dos desastres. Barragens de rejeitos de mineração. Risco. Direito comparado. Gestão e prevenção de emergências.

\footnotetext{
${ }^{1}$ Mestre em Direito Ambiental e Desenvolvimento Sustentável pela Escola Superior Dom Helder Câmara (ESDHC). Bacharel em Direito pela ESDHC. Chief Compliance Officer no Instituto de Direitos Humanos (IDH). Professor de Direito. Sócio e advogado no Sette \& Moreira Advocacia e Consultoria. E-mail: pedroadvdireito@gmail.com.

${ }^{2}$ Tenente do Corpo de Bombeiros Militar de Minas Gerais (CBMMG). Bacharel em ciências militares - prevenção e gestão de catástrofes pelo CBMMG. Técnico em Edificações e graduando em Engenharia de Produção Civil pelo CEFET-MG. E-mail: gonçalvespedro1997@gmail.com
} 


\title{
ENVIRONMENTAL JURISDICTION AFTER BRUMADINHO: PATHS TO EFFICIENT DISASTER GOVERNANCE FROM COMPARED LAW
}

\begin{abstract}
The study raises the right to disasters from the initial discussions about the risk society. Thus, recognizing the context of risk, from the perspective of Ulrich Beck, the issues of mining tailings dams, the potential for disasters that accompany these projects are punctuated, and the relationship of these risks with the tragedy in Brumadinho / MG. From this point on, the article aims to discuss, critically, the executive and legal management of the referred disaster, with the questioning about the efficiency of the Brazilian disaster law in the prevention and management of emergencies. To answer the question, we used comparative law, the hypothetical-deductive and dialectic method, with qualitative scores, to present US and European disaster law as a model for a new environmental jurisdiction in Brazil. Thus, what is concluded is the need to maintain the operability and permanence of the Law, outline strategies for stabilization and identification of victims, reduce future vulnerabilities, integrate State bodies and structure an effective preventive planning - from a solid jurisdiction. Thus, the need for a disaster right based on emergency management and prevention is pointed out, which justifies the work.
\end{abstract}

Keywords: Disaster law. Mining tailings dams. Risk. Comparative law. Emergency management and prevention

Artigo Recebido em 15/07/2020 e Aceito em 03/01/2021 


\section{INTRODUÇÃO}

A sociedade de risco se apresenta como um conceito moderno e seus desdobramentos atingem todas as esferas da vida. Isso porque, os riscos que acompanham os novos padrões sociais são constantes e demandam a gestão preventiva para evitar a consolidação em desastres.

É nesse sentido que a pesquisa se propõe a explanar sobre as barragens de rejeitos de mineração, dentro do contexto dos riscos, e os instrumentos da Política nacional de segurança de barragens como recursos para gestão preventiva. Não obstante, considerando as insuficiências da prevenção, o texto aborda o desastre ocorrido em Brumadinho/MG como exemplo da consolidação do risco em desastre.

A partir dessa perspectiva, objetivou-se demonstrar, de forma crítica, a gestão executiva e jurídica do desastre supramencionado com o questionamento acerca da eficiência do direito dos desastres brasileiro na prevenção e gestão de emergências. Para viabilizar as reflexões propostas recorreu-se ao direito comparado para demonstrar os avanços e insuficiências do direito dos desastres estadunidense e europeu na gestão de emergências.

Dessa forma, utilizando as conceituações e exposições comparadas, utilizou-se o método hipotético-dedutivo e dialético, bem como pontuações qualitativas extraídas da revisão de literatura, para a construção de perspectivas de um direito dos desastres que seja mais eficiente para a realidade brasileira. Assim, pela necessidade de gerir e evitar esses eventos, com foco na prevenção e mitigação de desastres, se justifica a pesquisa apresentada. 


\section{SOCIEDADE DE RISCO}

Os sistemas se baseiam, essencialmente, na expectativa e mobilização para a sobrevivência. Dessa forma, são indispensáveis as considerações acerca da gestão dos riscos e dos perigos, sobretudo se for considerado o contexto lecionado por Ulrich Beck (2011) em "Sociedade de Risco".

O paradigma da modernidade, aliado aos modelos de consumo e produção, levaram a uma série de tragédias e entraves que, até os anos 80 , eram vistas como "acidentes" decorrentes [e necessários] ao progresso econômico e crescimento dos centros urbanos. Não obstante, parece incontroverso que o agravamento dos problemas ambientais, estruturais e de segurança são relacionados aos processos de desenvolvimento do conhecimento - que não se preocupam em promover o controle dos efeitos de novos padrões tecnológicos, por exemplo. (BECK, 2011, p. 113)

Assim, diz-se que os indivíduos do século XXI vivem em um mundo fora do controle, pautado nas incertezas em razão da não mobilização para avaliação e análises dos riscos que os comportamentos sociais acarretam. Trata-se de um mundo governado inteiramente pelas leis da probabilidade, onde tudo é mensurável e calculável (BECK, 2006, p. 5).

As pessoas e o meio ambiente são submetidos aos efeitos do progresso e, por consequência, a riscos mais significativos. Muitas das vezes, esses riscos são superiores às capacidades de mitigação e proteção, de forma que se constitui um novo ser no espaço, o homo predator (KALOF, FITZGERALD, 2003, p. 98).

$\mathrm{Na}$ sociedade de risco, o indivíduo, percebendo as incertezas que o cercam, tende a promover reflexões baseadas nos pros e contras das interações "Homem-tecnologias", de forma que a formação de uma consciência possibilita o surgimento de métodos e mecanismos para aplacar os resultados da incerteza (FIGUEIREDO, 2018). 
Diz-se, portanto, que a análise de risco é o caminho para a teoria da decisão, que importa nos resultados relacionados à proteção social. Impera a constante avaliação das condicionantes dos comportamentos [novos e antigos] e a construção de planos estratégicos e táticos para garantia de uma ordem que - conforme as incertezas contemporâneas - não é estrutura permanente.

A disseminação de riscos - em especial os de natureza ambiental e tecnológica - é responsável por consequências que limitam determinadas transformações da modernidade. Isso porque, quando a sociedade toma ciência acerca dos riscos que produz, torna-se mais crítica e reflexiva acerca de si mesma, reagindo diante dos perigos que gera para si (JACOBI, 2005).

Nesse sentido, pensar a aplicação da sociedade de risco nos cenários reais importa para o entendimento da gravidade e dos comprometimentos frente aos empreendimentos. Isso porque, a ponderação acerca dos ônus das incertezas das tecnologias deve ser uma constante, sobretudo quando da pauta socioambiental. Ora, o equilíbrio ecológico é uma questão frágil e, muitas das vezes, irreparável. Assim impera o cuidado e a reflexão contínua acerca dos danos que podem ser acarretados pelas novas tecnologias que surgem no contexto da modernidade.

É a partir das noções acerca da contemporaneidade que se torna possível estabelecer quatro categorias de risco, conforme leciona Posner (2004). Em primeiro lugar, os desastres naturais, que independem da atuação humana e representam a própria dinâmica da natureza. Dentre elas, podemos citar os tsunamis, terremotos, erupções, por exemplo.

Em segundo lugar, estão identificados os desastres científicos. Estes englobam a atuação humana de forma direta, quando da manipulação de agentes químicos ou biológicos, além de também englobar os acidentes com aceleradores de partículas, por exemplo (DAMACENA, 2012). Em terceiro lugar estão os desastres intencionais, que envolvem o terrorismo - isto é, são arquitetados e criados para gerar o terror. 
Por fim, há os desastres de causa antropogênica. Estes são os riscos consolidados em catástrofe em razão da atividade ou atuação humana, mas não resguardam um nexo causal de intencionalidade. Neste rol é possível inserir as mudanças climáticas e os acidentes com barragens de rejeitos de mineração.

Estes últimos, inclusive, representam preocupação cada vez mais latente nas esferas públicas e privadas, na medida em que o paradoxo da mineração torna a avaliação dos riscos ainda mais complicada. Ora, se por um lado é notório que a atividade minerária representa uma parte indissociável da economia e tecnologia global, por outro lado é importante ressaltar que a atividade, além de poluidora, também guarda um potencial de desastres elevado.

Ademais, a quantificação dos riscos envolvendo a atividade - sobretudo a quantificação dos riscos das barragens de rejeitos - é uma tarefa árdua. Isso porque o gráfico de probabilidades desses empreendimentos não considera a curva normal, típica para cálculos de atividades cujos eventos são causados por inúmeros fatores aleatórios. No caso das barragens, o gráfico deve considerar fatores interligados, o que gera maior complexidade, na medida em que toda a probabilidade deve considerar a interação entre os sistemas.

É a partir desse contexto que as barragens de rejeitos sólidos de mineração devem ser avaliadas a partir de seus métodos construtivos, de forma que seja viabilizada a análise acerca das variáveis que influenciarão os riscos de desastres. Ademais, também devem ser consideradas as ações de acompanhamento constante que visam constatar a consolidação de probabilidades em realidades, bem como $o$ aprimoramento e atendimento às legislações que versem acerca da segurança desses empreendimentos - a fim de se evitar desastres como o ocorrido em Brumadinho, no ano de 2019. 


\section{BARRAGENS DE REJEITOS SÓLIDOS E A PREVENÇÃO DE DESASTRES}

Ao contrário das barragens civis, as barragens da mineração visam o acúmulo de rejeitos, que são a própria matéria-prima para a execução dos alteamentos (SABBO, 2017). Os referidos rejeitos nada mais são que materiais arenosos não plásticos, terra e rocha bastante finos que geram a lama, em virtude da alta plasticidade (LUZ et al, 2016). Atualmente, há três métodos de construção de barragens de rejeitos oriundos da atividade de mineração, quais sejam, método a jusante, método a montante e método da linha de centro (PEIXOTO, 2016).

O método a jusante foi desenvolvido para reduzir a liquefação nas zonas em que há ocorrência de abalos sísmicos. Primeiramente, constrói-se um dique e os alteamentos são construídos inteiramente uns sobre os outros, como paralelepípedos. Dessa forma, a linha de eixo da barragem se desloca a jusante (no sentido em que águas naturalmente correriam). Os próprios rejeitos mais grossos da barragem são utilizados para o alteamento, podendo a barragem chegar a grandes alturas. Referido método, embora mais seguro, ocupa uma grande área, devido à necessidade de aterro. Assim, o custo de sua implantação é alto, motivo pelo qual não é satisfatoriamente utilizado pelas mineradoras (SABBO, 2017) - reflexo de uma tendência de produção-consumo predatórios (SILVA, 2019).

O método a montante, por sua vez, consiste na formação de uma praia de rejeitos, a partir da construção de um dique inicial, que é constituído por materiais argilosos. Os rejeitos são escoados da parte de cima deste dique, formando a praia de rejeitos. Estes, por sua vez, solidificarão e servirão de fundação para os futuros diques a serem construídos. Ressalta-se que para que o material a ser lançado sirva como base para os novos alteamentos, é necessário que seja composto de $40 \%$ a $60 \%$ por areia. O método de construção a montante é menos dispendioso, em virtude da sua simplicidade 
na atividade construtiva, entretanto, é o método de menor coeficiente de segurança e o que causa a maioria das tragédias de ruptura de barragens no mundo (SABBO, 2017, p. 48).

Diz-se que "o método de alteamento à montante representa um desafio no âmbito geotécnico devido às tensões induzidas, potencial de liquefação e não consolidação do material utilizado como fundação" (CARDOZO; PIMENTA; ZINGANO, 2016).

O método de linha de centro, por sua vez, é intermediário entre os dois métodos supramencionados, sendo que a estrutura a ser construída se aproxima mais do método a jusante. Primeiramente, constrói-se um dique inicial e também são lançados rejeitos, formando uma praia. Todavia, os eixos de todos os diques iniciam-se do mesmo ponto. Neste caso, as vantagens e desvantagens se mesclam, uma vez que se apresenta como uma barragem de fácil construção, mas sujeita a escorregamentos. (SABBO, 2018). Trata-se, portanto, de um método "com mais riscos associados que o método de jusante e menos que o de montante" (CARDOZO; PIMENTA; ZINGANO, 2016).

Com relação aos principais problemas e riscos associados aos métodos construtivos, diz-se que o principal é aquele relacionado à instalação do sistema de drenagem. Isso, tendo em vista que os drenos são "responsáveis por prevenir excessos de poro pressão devido ao fluxo de água da barragem" (CARDOZO; PIMENTA; ZINGANO, 2016). Isso porque, essa pressão beneficia o movimento de partículos, de forma que, se não ocorrer a correta drenagem da estrutura, ocorrerá o "piping", que é a erosão interna da barragem, com eventuais escorregamentos. Isso ocorre em "solos pouco coesos, onde o gradiente hidráulico é maior que a coesão do solo" (MARQUES FILHO; GERALDO, 2002).

É nesse ponto que o direito pode influenciar a questão da construção de referidas estruturas, atuando em uma perspectiva que contribua para a prevenção e mitigação de desastres, na medida em que dita regulamentos 
básicos e normas mínimas para a garantia de uma realidade menos lesiva, independente da estruturação social.

No Brasil, o principal instrumento para a garantia das melhores técnicas, minimização dos impactos causados pelas barragens de mineração e gestão das probabilidades de desastres é o licenciamento ambiental que, apesar dos vícios - que provém da própria desvirtuação utópica do direito - ainda busca gerir a dignidade e segurança mínima em uma perspectiva global (SILVA, 2019).

No que diz respeito ao licenciamento e demais cuidados técnicos e jurídicos que envolvem a questão das barragens de rejeitos sólidos, importa dizer que assumem importância especial, tendo em vista os riscos potencialmente catastróficos que falhas nesse sistema podem acarretar. É o que se confirma, por exemplo, nos casos dos crimes ambientais nas cidades de Mariana e Brumadinho, em 2015 e 2019, respectivamente. Nesse sentido, a segurança ambiental, a partir de uma jurisdição preocupada com os desastres, é uma necessidade para a pós-modernidade capitalista - que se empenha na produção em massa. A sociedade de risco demanda, portanto, instrumentos para "lidar com o medo e a insegurança" (BECK, 2010, p. 93).

A partir desse contexto, os ensaios do direito dos desastres - em uma perspectiva de prevenção - apontam o licenciamento ambiental como instrumento de garantia da segurança mínima, além de estabelecer a responsabilização por danos causados por empreendimentos potencialmente poluidores e degradadores do meio socioambiental. É diante dessa realidade que a Política Nacional de Segurança de Barragens (PNSB) (Lei $\mathrm{n}$. 12.334/2010) é expressa em determinar que o empreendedor é responsável pela segurança da barragem - incumbindo a ele a promoção de medidas para garantir referida segurança. Concomitantemente, a responsabilidade pela fiscalização da segurança da barragem é da entidade "outorgante de direitos minerários a fim da disposição temporária ou permanente de rejeitos dessa atividade" (SILVA, 2018, p. 85). 
A efetivação da política pretendida é impulsionada pela alimentação do Sistema Integrado de Gestão de Segurança de Barragens de Mineração, de competência da Agência Nacional de Mineração (ANM), cujo objetivo é "gerenciar as estruturas no Brasil, contemplando módulos para empreendedores, auditores, fiscais da ANM, e da sociedade civil" (SILVA, 2018, p. 86). Também fica regulamentada a atribuição do órgão fiscalizador de manter anotações de engenheiros responsáveis, bem como a realização das recomendações técnicas, com revisões constantes acerca do cumprimento.

Dentro desse contexto, o Departamento Nacional de Produção Mineral (DNPM) também tratou de regulamentar revisões periódicas de segurança de barragens que ocorrerá: a) de três em três anos para estruturas com dano potencial associado alto; b) de cinco em cinco para risco de nível médio; c) de sete em sete para dano de risco baixo. Ademais, barragens reformadas, com alterações estruturais, devem ensejar relatórios de auditores "a cada 2 anos ou a cada 10 metros de alteamento, prevalecendo o que vier primeiro" (SILVA, 2018, p. 88).

Essas determinações e recomendações - desde o licenciamento até apresentação de relatórios pela PNSB - são medidas cujo fim é a satisfação da utopia socioambiental prevista no artigo 225, da Constituição Cidadã. Isso porque, promover medidas de prevenção, precaução, responsabilização e recuperação relacionadas à instalação e operação de barragens de rejeitos sólidos é também fortalecer uma perspectiva do direito dos desastres.

Não obstante, apesar de uma estruturação jurídica preventiva no cenário brasileiro, o que se verifica é que a gestão dos riscos se mostra insuficiente. Essa realidade, note-se, pode ser referendada pelo rompimento da Barragem B1, em Brumadinho, Minas Gerais, no ano de 2019.

\subsection{O desastre em Brumadinho/MG}

Quando são consideradas as causas que levaram ao rompimento da barragem supramencionada, é importante considerar que a gestão do 
empreendimento em si gerou impactos diretos na qualidade da gestão preventiva do risco. Bowker e Chambers (2017) apontam que existe uma relação entre o rompimento da barragem do Córrego do Feijão (Barragem I) e a qualidade do minério extraído na respectiva mina. Isso porque, as minas com minério de menor qualidade demandam barragens maiores (em razão do descarte de maior quantidade de resíduos) ao mesmo tempo em que são menos rentáveis (de forma que há um menor investimento em segurança por parte da empresa). Aliado a isso, os autores supra ressaltam que o lançamento do projeto "Barragem Zero" pela Vale S.A. guarda relação direta com o desastre-crime em Brumadinho. Isso porque, apesar do projeto ter perdido força em 2012 - em razão da baixa dos preços - e sido retomado em 2016, após o rompimento da barragem da Samarco, em Mariana, a Vale S.A. procurou estender a produção no Córrego do Feijão de forma considerável. Assim, apesar do planejamento inicial ter previsto o fim das operações no complexo em 2014, as atividades foram prorrogadas até o ano de 2016 - o que indica a possibilidade de que as barragens de rejeito tenham se aproximado da exaustão, com "baixa capacidade adicional de armazenamento" (Milanez et al, 2019, p. 63).

A própria construção da barragem I da mina do Córrego do Feijão indica falhas primordiais, na medida em que o método escolhido foi a montante, com realização de dez alteamentos e a constatação de falhas documentais, construtivas, "desempenho problemático e equipamentos de monitoramento defeituosos" (Milanez et al, 2019, p. 63). Ademais, a postura estatal - refletida na própria limitação sistêmica de disponibilização de fiscais e processos mais hábeis para garantia da segurança - já apontam para um descompromisso frente a governança dos desastres.

Toda essa realidade levou ao contexto do rompimento da Barragem I, da mina do Córrego do Feijão, no dia 25 de janeiro de 2019, às 12h28min. Foram 13 milhões de metros cúbicos de rejeitos lançados no meio ambiente, afetando 
diretamente a vida de mais de 300 pessoas que viviam ou trabalhavam na área de escoamento do rejeito.

Apesar da existência de equipamentos de segurança para uma eventual evacuação da área de auto salvamento, as sirenes não tocaram - em latente desconformidade com o que preconiza a legislação de prevenção de desastres. Dessa forma, as ondas de rejeito - que alcançaram 80 quilômetros por hora atingiram o refeitório e a área administrativa da Vale S.A. e, posteriormente, seguiu para Brumadinho. Os rejeitos alcançaram o Rio Paraopeba, vitimando também a fauna e flora fluviais. Cerca de 24 mil moradores de Brumadinho foram evacuados e o Corpo de Bombeiros Militar de Minas Gerais assumiu o posto de comando para resposta imediata à tragédia-crime.

\subsection{A gestão executiva do desastre em Brumadinho/MG}

Considerando que as diretivas de prevenção restaram falhas $e$ resultaram no rompimento da barragem B1, foi necessário executar um plano de gestão do desastre, articulado entre as três esferas federativas, que se transformou na maior operação de busca e salvamento do país. O governo federal criou o Conselho Ministerial de Resposta ao Desastre, composto por 15 cadeiras ministeriais, além de contar com a participação de entes estaduais e municipais, cujo principal foco foi monitorar e acompanhar as ações de resposta e recuperação adotadas, além de propor ações e medidas legislativas (SPINASSI, 2019).

A União decretou situação de calamidade pública, ratificou junto aos órgãos fiscalizadores a necessidade de vistorias em barragens que possuiam elevado risco de rompimento, além de aplicar multa inicial de 250 milhões de reais à Vale S.A., por meio do Instituto Brasileiro do Meio Ambiente e dos Recursos Naturais Renováveis (Ibama), tendo em vista o acometimento de danos à saúde humana, deterioração da habitualidade da área afetada, poluição hídrica e prática de injúria à fauna e flora (SPINASSI, 2019). 
O estado de Minas Gerais incumbiu-se, prioritariamente, em organizar e executar a operação para localizar e identificar as vítimas desaparecidas após o rompimento da barragem (MINAS GERAIS, 2019). O Corpo de Bombeiros Militar de Minas Gerais (CBMMG) foi o órgão estadual responsável pela articulação de tal operação e, por meio do Sistema de Comando de Operações (SCO), coordenou os esforços empregados, sejam estes provenientes de outros corpos de bombeiros, da Força Nacional, das Forças Armadas e de voluntários, que atuaram como agências de apoio (SPINASSI, 2019).

Além das atividades operacionais de busca, o estado mineiro empreendeu-se em outras tratativas, como a realização de investigações para apurar atividade estelionatária com objetivo de obter indenização indevida, por intermédio da Polícia Civil; a guarda material e isolamento dos locais desocupados, sendo tal tarefa desempenhada pela Polícia Militar; o restabelecimento de serviços e atividades essenciais, além de atender as necessidades das pessoas desalojadas e/ou desabrigadas, por meio da Defesa Civil; e monitoramento dos impactos ambientais e adoção de medidas que visavam a mitigação das nocividades instaladas sobre a fauna e flora, tendo 0 Sistema Estadual de Meio Ambiente e Recursos Hídricos (Sisema) como responsável por tal função. Por sua vez, o ente municipal executou multa contra à Vale S.A., devido à reincidência da empresa em face do desastre em questão (SPINASSI, 2019).

Paralelo à integração técnico-operacional, os entes federativos também promoveram um intercâmbio na área da saúde, mediado pelo Ministério da Saúde em conjunto com as Secretarias de Saúde Estadual e Municipal. Tal diálogo, a priori, visou 0 monitoramento das condições de saúde e ocupacionais dos profissionais envolvidos nas buscas e que estavam expostos à lama de rejeitos constituída de metais pesados e demais substâncias tóxicas. Posteriormente, ocorreu a proposição de estudos que visassem 0 monitoramento do estado de saúde da população de Brumadinho, de forma 
longitudinal, bem como um estudo específico para a saúde infantil das crianças do município (BRASIL, 2020).

Assim, observou-se, durante a fase executiva da resposta do desastre do rompimento da Barragem B1, em Brumadinho, uma associação e vinculação das ações adotadas pelos entes públicos, sobretudo das esferas federais e estaduais, que buscaram monitorar e coordenar as condutas empregadas, além de prover ações operacionais articuladas visando a localização de vítimas desaparecidas e amparo daqueles que por efeito do incidente acentuaram a precariedade de moradia, serviços básicos e meios de subsistência.

\subsection{A gestão jurídica do desastre em Brumadinho/MG e as insuficiências da governança do desastre em Brumadinho/MG}

Se por um lado a gestão executiva do desastre foi marcada pelo empenho conjunto de agências que visaram a localização e identificação de vítimas desaparecidas, além de atender às necessidades daquelas que, em algum grau, sofreram danos socioeconômicos e psicológicos, por outro lado, os órgãos de Justiça estiveram empenhados em garantir responsabilizações civis e criminais, assegurando indenizações às pessoas afetadas pelo desastre, e promovendo o debate da modificação de normas que versam sobre a segurança de barragens.

Nesse sentido, após um ano de investigações realizadas pelo Ministério Público de Minas Gerais (MPMG), em conjunto com a Polícia Civil de Minas Gerais (PCMG), foi apresentado à justiça denúncia em que se indicia dezesseis pessoas pelos crimes de falsidade ideológica, homicídio simples, lesão corporal, dano simples e qualificado, danos à fauna aquática e poluição qualificada. No mesmo sentido, duas pessoas jurídicas - a empresa Vale S.A. e a empresa alemã, Tüv Süd, responsável pelos certificados de segurança da barragem - também foram indiciadas pelos crimes ambientais supracitados (MINAS GERAIS, 2020). 
De acordo com o relatório da CPI da Barragem B1, elaborado pela Assembleia Legislativa de Minas Gerais, o desastre em questão não ocorreu por caso fortuito ou força maior, sendo, na verdade, causado pela omissão da empresa em face das condições de do empreendimento, implicando na execução de prática regulada por dolo eventual (MINAS GERAIS, 2019).

No mês seguinte à tragédia, foi apresentado o Termo de Ajuste Preliminar (TAP), que visou ratificar e sistematizar a Tutela Antecipada em Caráter Antecedente nos autos da ação no 5010709-36.2019.8.13.0024, que foi anunciada de maneira emergencial. As cláusulas previstas em tal TAP não excluem as medidas inseridas nos autos da Tutela Antecipada anterior, como 0 bloqueio e transferência da quantia de um bilhão de reais para conta judicial do Estado e determinação à Vale.S.A. de total colaboração ao poder público e à sociedade.

Assim, o TAP buscou a reparação sob dois prismas, quais sejam, o ambiental e o socioeconômico. Em relação ao meio ambiente, o TAP estabeleceu a responsabilidade da empresa em adotar medidas que visariam interromper o fluxo de lama e rejeitos que ainda carreavam das barragens rompidas, construindo e operando estruturas emergenciais. Ainda, com um prazo de sessenta dias a partir da data de divulgação do TAP, a empresa deveria apresentar um plano de remoção de todo o rejeito da área.

No que tange às reparações de cunho socioeconômico, o TAP estipulou que a Vale S.A. realizasse mapeamento da região, apresentando análise sobre as condições sanitárias, de salubridade e habitabilidade, sucedendo a remoção e disponibilização de nova moradia adequada para as famílias afetadas, assim como elaboração de plano global de recuperação socioeconômica para atendimento dessas mesmas famílias.

No mesmo sentido, ficou a cargo da empresa o pagamento de dívidas como financiamentos, arrendamentos e prestações mensais das pessoas atingidas pelo desastre, bem como promover o pagamento de um salário mínimo por mês pelo prazo de um ano para cada pessoa adulta afetada e 
residente no município de Brumadinho. Para adolescentes e crianças, a quantia ofertada foi de um meio e um quarto de salário mínimo, respectivamente.

O impacto do desastre também fez com que órgãos e autoridades públicas focalizassem esforços em identificar outros empreendimentos que apresentassem condições inadequadas de operação e segurança estrutural. Dessa maneira, a Agência Nacional de Mineração (ANM) sofreu aportes de efetivo, passando de 08 (oito) para 13 (treze) técnicos fiscalizadores, além de receber recurso materiais, por meio da Ação Civil Pública movida pelo Ministério Federal de Minas Gerais, que destinou a quantia de $\mathrm{R} \$ 42,7$ milhões à agência (BRASIL, 2020).

A ANM também foi responsável pela publicação de duas resoluções que versam sobre a segurança das barragens a nível nacional. A primeira delas, de no 4/2019, determinou que a técnica construtiva de alteamento à montante está proibida em todo o território nacional. Ademais, também determinou 0 descomissionamento dos empreendimentos construídos pela técnica. Ainda, vedou a construção e manutenção de instalações prediais na zona de autossalvamento.

A resolução no $13 / 2019$, por sua vez, atualizou a prorrogação do prazo da descaracterização das barragens construídas por alteamento à montante, conforme solicitação do Ministério Público Estadual de Minas Gerais, para que as empresas pudessem realizar tal ato com base em normas técnicas e de segurança.

Todavia, mesmo diante de todas as ações apresentadas, sejam estas realizadas pelo poder executivo ou pelo poder judiciário, a proximidade temporal entre o desastre em Brumadinho e o desastre em Mariana, em novembro de 2015, revelam que pouco se aprendeu sobre o potencial de destruição desses empreendimentos. Pouco eficientes foram os trabalhos realizados por parte do Poder Público durante mais de três anos, após a primeira tragédia, tendo em vista que o PL 3676/2016 - que propôs a vedação 
da instalação de barragens à montante de povoados e recursos hídricos - foi aprovado somente um mês após o rompimento da barragem em Brumadinho (PASSARINHO, 2019).

Ainda, mostrou-se latente a incapacidade efetiva de acionamento da população ou de mecanismos protocolares de condutas e de evasão no caso de rompimento de barragens. Os sistemas de segurança e acionamento existentes eram demasiadamente precários, sendo que nem mesmo foram capazes de salvar áreas administrativas e seus funcionários. Foram negligenciados os reais riscos do empreendimento, o que se agravou pelas omissões acerca das condições de segurança. Nessa conjuntura, a população, sobretudo a mais vulnerável, figura-se como a principal vítima de tais desastres, estando sujeita às injúrias decorrentes da mal administração pública que terceiriza para as próprias empresas a fiscalização de tais barragens.

\section{DIREITO DOS DESASTRES}

Se a gestão executiva e jurídica dos desastres se mostra cercada de entraves, mostrando-se ineficaz, sobretudo na perspectiva da prevenção, podese dizer que tais limitações decorrem da própria indefinição jurídica do termo desastre. É justamente a ausência de conotação jurídica para a palavra que gera tantas lacunas em uma legislação que, em tese, deveria abordar o tema de forma complexa e estruturada.

Diante dessa realidade, é importante se atentar para a necessidade de construir o Direito dos Desastres como um campo autônomo - tal qual o Direito Ambiental - garantindo a multidisciplinariedade de sua formação, na medida em que inúmeras áreas técnico-científicas são indispensáveis para garantir uma correta prevenção, resposta e gestão dos desastres e riscos. É o que já prevê a Lei 12.608/2012, que instituiu a Política Nacional de Proteção e Defesa Civil. 
Inclusive, é justamente por meio dos princípios que fundamentam a legislação citada, quais sejam, a prevenção e a precaução, que é possível afirmar que o objetivo primeiro do Direito dos Desastres é promover a manutenção da segurança socioambiental por meio da mitigação, resposta de emergência, compensação e reconstrução.

A partir dessa constatação, afirma-se que a melhor medida para lidar com os desastres é a prevenção da consolidação dos riscos em desastres. Todavia, é importante considerar que na sociedade de risco, em que não há maneiras de se domar os riscos em absoluto, também é importante trabalhar a mitigação e resposta aos desastres.

É nesse contexto que a pesquisa demonstrará o tratamento dos desastres na realidade internacional para, posteriormente, apontar o sistema brasileiro, suas insuficiências e propostas para um Direito dos Desastres eficiente e eficaz.

\subsection{Direito dos Desastres nos Estados Unidos da América (EUA) e Europa}

Com foco em dois eixos principais - reparar e prevenir - a legislação de desastres estadunidense garante a existência de um plano com sete critérios de abordagem dos desastres, quais sejam, treinar, equipar, planejar, organizar, melhorar, avaliar e exercitar. Esses preceitos estão inseridos em uma realidade de organização de resposta, que se organiza no National Incident Management System - NIMS ${ }^{3}$.

Referido sistema, que se orienta por uma macro realidade do Sistema de Comando de Incidentes, é coordenado pelo Departamento de Segurança Nacional. Este departamento é constituído por órgãos de caráter regional e local que podem responder imediatamente, no caso da ocorrência de algum desastre.

\footnotetext{
${ }^{3}$ Sistema nacional de gerenciamento de incidentes (tradução nossa).
} 
Nesse ponto, é importante pontuar que toda a organização orgânica dos departamentos e agências de prevenção e resposta a desastres nos EUA se orienta por uma legislação que é fundamentada pelo aprendizado com eventos do passado. O núcleo orientador da jurisdição é, nesse caso, o Stafford Act, de 1988, que garante respostas relacionadas às assistências federais e a integração entre as esferas estaduais e locais.

A complementação normativa foi realizada pela edição da Disaster Mitigation Act, de 2000, que traça planejamentos relacionados à precaução dos riscos, atendo-se também às questões relacionadas à prevenção dos eventos. A partir daí, foi possível ao governo, em todas as esferas, ponderar as questões assistenciais posteriores aos desastres.

Não obstante, o maior avanço na legislação de desastres ocorreu nos EUA após o atentado terrorista nas "Torres Gêmeas", em 2001, que resultou na criação de inúmeros órgãos para prevenção de ataques terroristas. O principal desses órgãos foi o Department of Homeland Security - DHS que, apesar de também englobar respostas a desastres naturais, acabou influenciando negativamente e minando as forças e investimentos na prevenção de desastres - na medida em que a gestão do Presidente Bush passou a orbitar nos gastos bélicos (BARCESSAT, 2017).

Conforme leciona Barcessat (2017, p. 73), "o preço pelo abrandamento das políticas de prevenção e resposta a desastres foi pago já em 2005 quando da ocorrência do furacão Katrina, revelando que, apesar da criação do DHS, o país continuava mal preparado para responder e se recuperar de uma grande catástrofe." E foi justamente esse episódio que levou o Congresso a editar o Post-Katrina Emergency Reform Act, de 2006.

A partir daquele momento, todos os Estados foram compelidos a providenciar e estabelecer planos de emergência com gestão centralizada em uma agência nacional. O diretor da agência, note-se, foi encarregado de coordenar a resposta quando da ocorrência dos desastres. 
Referida integração permite que, no caso de serem necessários recursos superiores ao que pode dispor o Estado-membro, seja solicitado ao governo federal a complementação - que depende de declaração presidencial. No caso de aprovação, os recursos são transferidos para a esfera estadual a partir do fundo nacional de desastres. Ademais, também é possível que esses recursos sejam notificados antes mesmo da ocorrência dos desastres, em uma espécie de reserva, de forma a garantir que, quando da consolidação dos desastres, os recursos federais sejam fornecidos rapidamente - principalmente nos casos de desastres que envolvem agentes químicos, nucleares e biológicos.

Essa legislação trouxe, ainda, uma definição jurídica para o termo "incidente catastrófico", passando a se referir a "qualquer desastre natural, ato de terrorismo ou outros desastres provados pelo homem que resultem em níveis extraordinários de causalidades, danos ou perturbações que afetem gravemente a população" (EUA, 2006). E é justamente a conceituação jurídica que reforçou, em âmbito nacional, a importância da The National Environmental Policy Act - NEPA, que estabelece as condutas de precaução e prevenção quando da avaliação dos empreendimentos.

Todavia, é importante ressaltar que, apesar das mobilizações pós Katrina, a avaliação dos riscos dos empreendimentos ainda está longe de seguir os parâmetros ideais para um direito dos desastres absolutamente eficiente. Isso porque, as próprias agências de segurança, aliadas ao judiciário, exigem a realização de estudos prévios acerca dos empreendimentos tão somente no caso de impactos potenciais significativos.

Assim, só será considerada a necessidade de estudos aprofundados após avaliada "a repercussão na saúde pública, as características geográficas originais da área, o potencial efeito da ação e o grau de controvérsia da ação" (BARCESSAT, 2017, p. 75). Após, é observado também a magnitude das potencialidades de impacto e desastres (FARBER, 2009). 
Conforme leciona Barcessat (2017), a problemática que cerca esta avaliação são os critérios que levam à dedução acerca da significância de um risco e de seu possível impacto no caso de desastre. Concomitantemente, os Tribunais pouco têm contribuindo para o avanço na questão, na medida em que determinam que os estudos não precisam estar focados em consequências que possam ser julgadas como especulativas - o que, no teor desta pesquisa, pode ser entendido como inobservância do princípio da precaução.

É justamente essa realidade que também reforça a necessidade da discussão acerca da responsabilização no caso de desastres -integrando a esfera do direito dos desastres. Nesse caso, é importante apontar algumas especificidades da legislação estadunidense, que prevê os acts of God.

Referidos eventos constituem as tempestades, terremotos e outros eventos naturais que, poucas vezes, sofrem contribuições humanas diretas. Não obstante, no caso de ser constatada a negligência concausal associada a estes desastres, vige nos EUA o dever da indenização.

É em razão disso que os seguros, obrigatórios e privados, são tão importantes naquele país, na medida em proporcionam alguma segurança de reparação para as vítimas desses eventos. Ademais, diferentemente do que ocorre no Brasil, por exemplo, o próprio Estado surge como a figura do segurador residual.

Assim, se por um lado as empresas de seguros se utilizam da alta probabilidade de ocorrência de desastres para inflar a tensão entre os segurados, por outro, o governo federal assume os riscos que são banalizados pelas empresas privadas. Dessa forma, além do pagamento de indenizações por parte do Estado, também são fornecidos empréstimos para as vítimas de desastres - o que possibilita a recuperação.

Não obstante, é importante pontuar que esse contexto gera altos custos para o governo, na medida em que os fundos demandam alimentação constante. Esse contexto, note-se, gera constantes discussões e alterações 
legislativas que, gradualmente, levam a realidade de esforços de reparação e recuperação para a esfera da prevenção e precaução - a exemplo do que já ocorre na Europa.

Ora, considerando que o Tratado de Lisboa conferiu à União Europeia a competência para coordenar as atividades de proteção civil (ARAGÃO, 2017), foram criadas duas vertentes principais relacionadas aos desastres dentro do direito comunitário, quais sejam, prevenção dos riscos e intervenção na consolidação do desastre.

No que tange à prevenção, a regulação da temática pode ser verificada no Regulamento 1726/2003, do Conselho Europeu, na Diretiva 60/2007, que trata especificamente da "prevenção de catástrofes naturais e humanas" (BARCESSAT, 2017, p. 79). Referida legislação surgiu a partir de importante característica do direito dos desastres, que é a resposta do presente aos eventos do passado.

Dessa forma, considerando os inúmeros desastres que marcaram o início do século XXI na Europa, incluindo os alagamentos provocados pelo rio Danúbio e Elba, foi repensada toda a gestão de riscos de desastres sobretudo aqueles que envolvem inundações. Isso, considerando o potencial de destruição ecológica causada pelas cheias dos rios e mares, bem como os impactos ecológicos e sociais desses eventos - principalmente se forem consideradas as probabilidades de destruição de fábricas em que existem produtos tóxicos.

É nesse sentido que a União Europeia recomenda a seus Estadosmembros a estruturação de planos de gestão de riscos que considerem as bacias hidrográficas, os efeitos transfronteiriços dos danos e o estabelecimento de abertura para integração de toda a comunidade para afastar os riscos de desastres. Esses planos, conforme a diretriz da própria União Europeia, devem constar ações distintas das que outrora já foram tomadas, isto é, devem ser planos obrigatoriamente inovadores (SUN, 2017). 
Por instrução da Diretiva 60/2007, a gestão de riscos também deve considerar melhores técnicas, além de prever a necessidade da utilização sustentável do solo. Acompanhando essa questão, os planos também devem contar com "a instauração de um sistema de informação, a atualização contínua, a observação aos princípios da solidariedade, da responsabilidade compartilhada e o incentivo à participação popular" (BARCESSAT, 2017, p. 81). Assim, o que se busca é a integração interdisciplinar para prevenção e precaução de desastres.

Dessa forma, o que se verifica é que a União Europeia apresenta propostas legislativas bem desenvolvidas na esfera do direito dos desastres, se pautando - prioritariamente - nas medidas que levam à redução dos riscos e às respostas emergenciais nos casos de consolidação de riscos em desastres.

\section{MULTIDIMENSIONALIDADE DO DIREITO DOS DESASTRES: UMA PROPOSTA PARA O BRASIL}

Considerando as principais características do Direito dos Desastres nos países do eixo Norte, é possível pensar caminhos de fortalecimento para a seara no Brasil. Dessa forma, pelo direito comparado viabiliza-se o aperfeiçoamento das práticas de prevenção de eventos e da gestão do desastre em si.

Para tanto, é importante pontuar que são três as principais leis brasileiras que dispõe sobre os desastres, quais sejam, Decreto 7.257/2010, Lei 12.340/2010 e Lei 12.608/2012. Note-se que se trata de legislação recente e ainda em construção.

No que tange à Lei 12.340/2010, dispõe acerca da "transferência de recursos da União aos órgãos e entidades dos Estados, Distrito Federal e Municípios para a execução de ações de resposta e recuperação nas áreas atingidas por desastre, e sobre o Fundo Especial para Calamidades Públicas." Para que a União preste o apoio complementar é necessário que os Estados 
tenham a situação de emergência ou estado de calamidade pública reconhecidos, conforme a inteligência do artigo $3^{\circ}$.

Incumbiu ao Decreto 7.257/2010 regulamentar os requisitos necessários para a consolidação da transferência desses fundos, que se dá por meio de Portaria. Todavia, é importante pontuar que os critérios podem ser relativizados ou substituídos, desde que o impacto do desastre no meio socioambiental seja notório e incontroverso.

Nesse ponto, cabe ressaltar que o principal avanço da legislação de desastres no Brasil ocorreu com a publicação da Lei 12.608/2012, a Política Nacional de Proteção e Defesa Civil (PNPDEC) - que se propôs a corrigir a legislação anterior que era mais preocupada com as medidas de gestão do desastre que com as medidas de prevenção.

Com relação à PNPDEC, foi a responsável por delegar à União, Estados, Municípios e Distrito Federal o dever de promoverem as medidas para redução dos riscos. Ademais, apesar de não utilizar expressamente o termo "precaução", a lei estabelece a necessidade de antecipar riscos que sejam marcados por incertezas técnicas e científicas. Dessa forma, deve ocorrer um esforço contínuo e integrado para a redução das probabilidades de desastres, a incorporação da minimização do risco e das ações de defesa civil nos elementos de gestão territorial, a produção de alertas prévios e a integração das comunidades nos planejamentos de respostas.

Além disso, outros dois pontos da PNPDEC merecem destaque. O primeiro diz respeito ao incentivo pela construção de cidades resilientes e que desenvolvam um processo de urbanização sustentável - o que facilita a previsão, prevenção e resposta no caso de desastres. O segundo ponto diz respeito aos planos de socorro, com prestação de resgate e abrigo dos afetados, além dos ensinamentos de autoproteção.

Apesar das referidas leis delinearem de forma interessante alguns aspectos de prevenção e gestão de desastres, é importante pontuar que a legislação carece de uma construção mais detalhada, que se atente para os 
avanços já alcançados em outros países. É o caso da responsabilização do Estado perante a ocorrência desses eventos.

Se nos Estados Unidos da América, por exemplo, o Poder Público surge como um segurador da população (BARCESSAT, 2017) - para cobrir as causas não contempladas pelas seguradoras privadas -, no Brasil a discussão acerca da responsabilidade do Estado em promover indenizações é cercada de dúvidas. Isso porque, apesar de ser adotada a Teoria do Risco Administrativo nas matérias ambientais (responsabilização objetiva, que independe de dolo ou culpa), no caso da ocorrência de desastres há invocação de excludentes do nexo causal - sobretudo caso fortuito e força maior.

Assim, apesar da doutrina já discutir o não cabimento das citadas excludentes em uma sociedade de risco, em que nenhum desastre é puramente natural, a tendência da jurisprudência ainda é afastar a responsabilidade do Estado e incluí-lo no título executivo tão somente quando frustradas todas as possibilidades de execução daquele que, primordialmente, deu causa ao dano (BARCESSAT, 2017).

O que se verifica, nesse caso, é que o Direito dos Desastres demanda uma discussão acerca da responsabilidade civil muito mais profunda que aquela travada na seara do Direito Ambiental. Isso porque há incompatibilidades entre a doutrina tradicional e as demandas geradas pelos riscos da sociedade pós-industrial.

Ademais, é necessário integrar a multidimensionalidade da sustentabilidade ao desenvolvimento e aprimoramento do Direito dos Desastres no Brasil. Assim, além de considerar as esferas social, ambiental e econômica na prevenção e gestão dos riscos e desastres, impera a consideração das dimensões jurídico-política e ética.

No que diz respeito à dimensão jurídico-política, é necessário que a legislação solidifique caminhos e condições para que o acesso à Justiça - pósdesastre, principalmente - se dê de forma democrática, eficiente e célere. Isso porque é preceito do paradigma da sustentabilidade a razoável duração dos 
procedimentos (GOMES, FERREIRA, 2017), como forma de efetivação da própria justiça.

Por outro lado, a integração de uma dimensão ética da sustentabilidade no Direito dos Desastres se relaciona às noções de justiça intergeracional (GOMES, FERREIRA, 2017). Isto quer dizer que, pelo aprendizado e gestão dos riscos no presente, as futuras gerações devem herdar um contexto de menores riscos e consolidação dos desastres - o que se justifica pela solidariedade e fraternidade. Diz-se, então, acerca da necessidade de um Direito dos Desastres multidimensional, assim como é o Direito Ambiental.

Ainda no que tange à prática do direito na matéria de desastres, é importante que os órgãos de justiça - nas esferas estadual e federal, principalmente - promovam o encontro permanente para o alinhamento de condutas e ações. Assim, contribui-se para a construção de um aparato de justiça forte e eficiente, que evite estratégias desencontradas e que terminem por frustrar as pretensões dos afetados.

Paralelamente, o Direito dos Desastres deve estar preocupado em garantir a operacionalidade do Direito (quando dos desastres); evitar a ausência do Direito; garantir - por meios legais - a estabilização e reacomodação de vítimas; reduzir as vulnerabilidades sociais, ambientais e econômicas futuras.

No mesmo sentido, é importante que os legislativos federal e estaduais também se organizem de forma tática e estratégica para dar seguimento na estruturação de um Direito dos Desastres que ainda é recente no Brasil. Assim, por meio de leis construídas sobre bases técnicas e com cunho factível, será possível enrobustecer as ações para prevenção e gestão de desastres no país.

Ao mesmo tempo, é dever das agências relacionadas às atividades de defesa civil promover $\mathrm{o}$ aperfeiçoamento e treinamento constante dos encarregados pelas respostas aos desastres - sobretudo pela integração de todos os órgãos do Estado. E, mais importante ainda, deve ser estruturado planejamento que viabilize o emprego de servidores públicos na fiscalização de 
empreendimentos que representam risco - na medida em que delegar às próprias empresas a tarefa de fiscalização ofende o dever do Estado de garantir o bem-estar socioambiental das comunidades, com vilipêndio aos valores segurança e vida.

Por fim, é necessário que o Estado e sociedade brasileira se apropriem da memória do desastre em Brumadinho como forma de efetivar a máxima que coroa o Direito dos Desastres: "aprender com os erros do passado". Assim, recorrendo ao direito comparado mas, principalmente, às experiências já vividas pelas comunidades e Estado, a construção de um Direito dos Desastres eficaz e eficiente se fará pelas considerações das vacâncias, erros, acertos e ações desenvolvidas no município de Brumadinho, desde janeiro de 2019.

A partir da análise apurada a respeito do caso concreto, a criação de uma racionalidade interdisciplinar garantirá um aparato legislativo que considere tanto a prevenção e precaução quanto a gestão eficiente do desastre, com o oferecimento de uma estabilidade pela normatividade e execução. Efetivar o Direito dos Desastres com rigor técnico, científico e jurídico é, portanto, consolidar uma jurisdição ambiental democrática e fortalecedora da dignidade socioambiental.

\section{CONSIDERAÇÕES FINAIS}

Em um primeiro momento a pesquisa trouxe considerações acerca da sociedade de risco, em um contexto pós-industrial. Assim, o que foi demonstrado é que as tecnologias que acompanham a contemporaneidade são as principais responsáveis pela construção de infinitos riscos que - se não prevenidos - podem se consolidar em desastres.

Como exemplo das referidas tecnologias, foram considerados os empreendimentos de barragem de rejeitos de mineração como grandes contribuintes para o contexto de risco - sobretudo quando analisadas as técnicas construtivas que não necessariamente representam as melhores alternativas para a construção das estruturas. É o que se referenda com a 
explanação a respeito do rompimento da barragem $\mathrm{B} 1$, no município de Brumadinho/MG. Aquela barragem, conforme demonstrado, foi construída pelo método a montante e sofreu reiterados alteamentos que contribuíram para sua liquefação.

A partir da caracterização do evento em si, foi desenvolvida a análise da gestão do desastre nas perspectivas executiva e jurídica. Isto é, foi analisa a resposta do Estado perante o rompimento no que tange ao socorro, busca e realocação das vítimas, mas também no que diz respeito à mobilização dos órgãos de Justiça para garantir a responsabilização. Por meio da explanação desse contexto, foram apontadas as suficiências e insuficiências da atuação estatal, considerando que o Direito dos Desastres brasileiro é uma seara extremamente recente e em formação.

Assim, a partir dessas constatações, utilizou-se do direito comparado principalmente as legislações estadunidense, europeia e japonesa - para demonstrar modelos de prevenção e gestão de emergências em realidades mais desenvolvidas e consolidadas que a brasileira.

Dessa forma, à luz do que já vem sendo colocado em prática nos países do eixo Norte, indicou-se a necessidade de que o Direito dos Desastres no Brasil se dedique às ações preventivas, com importação de um contexto multidimensional que considere as dimensões social, ambiental, econômica, jurídico-política e ética. Ademais, também deve ser considerada uma discussão que extrapole o Direito Ambiental e o cabimento de excludentes de culpabilidade na responsabilização civil, na medida em que o Direito dos Desastres é um ramo autônomo do Direito.

Por fim, foi considerado indispensável o alinhamento dos órgãos estatais - do Judiciário e Poder Público - como forma de garantir posicionamentos e ações estrategicamente encontradas. Assim, pelo fortalecimento jurídico, legislativo e executório do Direito dos Desastres, que se faz com o aprendizado dos erros do passado, será construída uma jurisdição ambiental coroada pela dignidade socioambiental. 


\section{REFERÊNCIAS}

ARAGÃO, Alexandra. Prevenção de riscos na União Europeia: o dever de tomar em consideração a vulnerabilidade social para um protecção civil eficaz e justa. Disponível em: https://journals.openedition.org/rccs/174. Acesso em: 16.06.2020.

BARCESSAT, Ana Clara Aben-Athar. Os desastres e o Direito Ambiental: governança, normatividade e responsabilidade estatal. (Dissertação de Mestrado). São Paulo, Pontifícia Universidade Católica de São Paulo. 2017.

BECK, Ulrich. Incertezas fabricadas. IHU Online, São Leopoldo, maio, 2006.

BECK, Ulrich. Sociedade de Risco: Rumo a uma outra modernidade. Rio de Janeiro: Editora 34. 2011.

BECK, Ulrick. Sociedade de Risco: rumo a uma outra modernidade. Rio de janeiro: Editora 34, 2010.

BOWEKER, L. N.; CHAMBERS,D. M. In the dark shadow of the supercycle tailings failure risk \& public liability reach all time highs. Environments, 4(75), 1-21. Brandt Meio Ambiente. (2010). Mina Córrego do Feijão - Relatório de Avaliação de Desempenho Ambiental (RADA). Belo Horizonte: Brandt Meio Ambiente. 2017.

BRASIL. UM ANO DO DESASTRE DA VALE. Boletim Epidemiológico. Secretaria de Vigilância e Saúde; Ministério da Saúde. Número Especial. 2020.

BRASIL. Um ano após desastre de Brumadinho, leis, vistorias e fiscalizações de barragens vêm sendo intensificadas no Brasil. Agência Nacional de Mineração, 2020. Disponível em: < http://www.anm.gov.br/noticias/um-ano-apos-desastre-de-brumadinho-leisvistorias-e-fiscalizacoes-de-barragens-vem-sendo-intensificadas-no-brasil>. Acesso em 14 de julho de 2020.

CARDOZO, F.A.C; PIMENTA, M.M; ZINGANO, A.C. Métodos Construtivos de barragens de rejeitos de mineração: uma revisão. Holos, ano 32, v. 08, pp. $77-$ 85. 2016.

DAMACENA, Fernanda Dalla Libera. A formação sistêmica de um direito dos desastres. Dissertação de mestrado. Universidade do Vale dos Rio dos Sinos. 2012. 
DAMACENA, Fernanda Dalla Libera. A governança dos desastres ambientais no direito comparado norte-americano e europeu. RIL Brasília, n. 208, out-dez, 2015.

FARBER, Daniel. Confronting Uncertainty under NEPA, Issues in Legal Scholarship Balancing the Risks: Managing Technology and Dangerous Climate Change, v. 8, n. 3, p. 1, 2009.

FIGUEIREDO, Clayson Marlei. Os aspectos dos desastres sobre a ótica da sociedade de risco. Revista FLAMMAE, v. 04, n. 11, p. 301-315. 2018.

GOMES, Magno Federici. FERREIRA, Leandro José. A dimensão jurídicopolítica da sustentabilidade e o direito fundamental à razoável duração do procedimento. Revista do Direito, Santa Cruz do Sul, v. 2, n. 52, p. 93-111. 2017.

JACOBI, Pedro Roberto. Educação ambiental: o desafio da construção de um pensamento crítico, complexo e reflexivo. Educ. Pesqui., São Paulo, v. 31, n. 2, Aug. 2005.

KAGAWA. Guia de prevenção em caso de desastres naturais para residentes estrangeiros (versão em português). 2020. Disponível em: https://www.pref.kagawa.lg.jp/content/etc/subsite/kokusai/upfiles/sl31lu1601312 05506_f15.pdf. Acesso em: 12 jul.2020.

KALOF, Linda. FITZGERALD, Amy. Reading the trophy: exploring the display of dead animals in hunting magazines. Routledge. London. Vol. 18, 끄. 2, 2003.

LUZ, Adão. et al. Tratamento de Minérios. 5. Ed. Rio de Janeiro: Lumens luris. 2016.

MANTELLI, Gabriel Antonio Silveira. Dos desastres socioambientais ao direito: fatores aplicáveis e breve quadro jurídico. Revista Direito UFMS, Campo Grande, v. 4, n. 1, p. 74-95. 2018.

MARQUES FILHO, P. L., \& Geraldo, A. Barragens e Reservatórios. In: A. M. dos S. Oliveira \& S. N. A. de Brito (Ed.). Geologia de Engenharia. São Paulo: ABGE. 2002.

MINAS GERIAIS. Brumadinho: a maior operação de busca e salvamento do Brasil. Defesa Civil de Minas Gerais. Disponível em: $<$ http://www.defesacivil.mg.gov.br/index.php/component/gmg/page/575resgatebrasil>. Acesso em 10 de jul.2020. 
MINAS GERAIS. Síntese do relatório da CPI da Barragem de Brumadinho. Assembleia Legislativa de Minas Gerais, 2019. Disponível em: $<$ https://www.almg.gov.br/export/sites/sites/cpi-

barragem/.content/arquivos/relatorio-brumadinho.pdf>. Acesso em 14 de julho de 2020.

MINAS GERAIS. MPMG e PCMG finalizam investigações sobre o rompimento da barragem em Brumadinho; 16 pessoas são denunciadas por homicídio qualificado e crimes ambientais. Ministério Público de Minas Gerais, 2020. Disponível em: < https://www.mpmg.mp.br/comunicacao/noticias/mpmg-e-pcmg-finalizaminvestigacoes-sobre-o-rompimento-da-barragem-em-brumadinho-16-pessoassao-denunciadas-por-homicidio-qualificado-e-crimes-ambientais.htm>. Acesso em 14 de julho de 2020.

MINISTÉRIO PÚBLICO DE MINAS GERAIS. Termo de Ajuste Preliminar. 2019. Disponível em: < http://www.mpf.mp.br/mg/sala-deimprensa/docs/minuta-tap-brumadinho/view>. Acesso em 14 de julho de 2020.

PASSARINHO, Nathalia. Tragédia em Brumadinho: As 5 lições ignoradas após tragédia de Mariana. BBC News Brasil, 2019. Disponível em: $<$ https://www.bbc.com/portuguese/brasil-47077083>. Acesso

PEIXOTO, Ricardo Fiorotti. Utilização de Rejeitos de barragens de minério de ferro na construção civil. Ouro Preto: UFOP. 2016.

POSNER, Richard. Catastrophe: Risk and Response. New York: Orford University Press, 2004. p. 12.

SABBO, Gabriela Rodrigues. Et al. Barragens de Rejeitos de Mineração. Revista Engenharia em Ação UniToledo, Araçatuba. V. 2, n. 1, p-3-15, janago. 2017.

SILVA, Leila Cristiana do Nascimento e. Barragens de rejeito da mineração: análise do sistema de gestão do Estado de Minas Gerais. Rio de Janeiro: Lumen Juris, 2018.

SILVA, Pedro Henrique Moreira da. A bio-necropolítica das injustiças ambientais: das vulnerabilidades humanas à tragédia-crime em Brumadinho/MG. (Dissertação de Mestrado). Escola Superior Dom Helder Câmara. 2019. Disponível em: http://domhelder.edu.br/wpcontent/uploads/2020/06/DISSERTA\%C3\%87\%C3\%83O-PEDRO-HENRIQUEFINAL-CORRIGIDO-06.2020.pdf. Acesso em: 14 jul.2020. 
SPINASSI, Cláudio André. Mapeamento e avaliação da maior operação humanitária do Brasil sob a ótica do Lean Manufacturing. Trabalho de Conclusão de Curso. Universidade Tecnológica Federal do Paraná. Ponta Grossa-PR, 2019.

SUN, Lisa Grow. Smart Growth. In: CARVALHO, Délton Winter (org.). Estudos aprofundados em Direito dos Desastres: interfaces comparadas. Curitiba: editora Prismas, 2017, p.153.

USA. Post-Katrina Emergency Reform Act. 2006. Disponível em: https://www.doi.gov/sites/doi.gov/files/uploads/Post_Katrina_Emergency_Mana gement_Reform_Act_pdf.pdf. Acesso em: 16.06.2020.

USA. The National Environmental Policy Act of 1969. Disponível em: https://www.epa.gov/nepa. Acesso em: 16.06.2020. 